\title{
Theropod footprints from the Lower Cretaceous Cangxi Formation in the Northern Margin of the Sichuan Basin, China
}

\author{
Lida Xing a, b* , Martin G. Lockley c, Bolin Tong ${ }^{\text {b }}$, Hendrik Klein ${ }^{\text {d }, ~ W . ~ S c o t t ~ P e r s o n s ~ I V ~ e, ~ G u a n g z h a o ~ P e n g ~}{ }^{\text {, }}$ \\ Yong Ye ${ }^{f}$, Miaoyan Wang ${ }^{b}$ \\ a Key Laboratory of Vertebrate Evolution and Human Origins of Chinese Academy of Sciences, Institute of \\ Vertebrate Paleontology and Paleoanthropology, Chinese Academy of Sciences, Beijing 100044, China. \\ ${ }^{b}$ School of the Earth Sciences and Resources, China University of Geosciences, Beijing, 100083, China. \\ ' Dinosaur Trackers Research Group, University of Colorado, Denver 80217, USA. \\ d Saurierwelt Paläontologisches Museum Alte Richt 7, D-92318 Neumarkt, Germany. \\ e Mace Brown Museum of Natural History, Department of Geology and Environmental Geosciences, College \\ of Charleston, Charleston 29401, USA. \\ ${ }^{f}$ Zigong Dinosaur Museum, Zigong, Sichuan, China. \\ ${ }^{*}$ Corresponding author. Lida Xing: xinglida@gmail.com
}

(C) The Authors 2021

\section{ABSTRACT}

A single well-preserved theropod trackway identified as Eubrontes was discovered in the Lower Cretaceous (Berriasian-Valanginian) Cangxi Formation on the northern margin of the Sichuan Basin This is the first report of tracks from this formation. The occurrence is consistent with reports of theropod dominated ichnofaunas from broadly coeval deposits such as the Feitianshan Formation in southern parts of the basin. There is growing evidence that Eubrontes and Eubrontes-like tracks are common in the Lower Cretaceous of Sichuan Province.

\section{ARTICLE HISTORY}

Received: 15-01-2021

Revised: 06-03-2021

Accepted: 12-03-2021

\section{KEYWORDS}

Theropod tracks

Eubrontes

Ichnofaunas
Introduction

The northern margin of the Sichuan Basin extends through Cangxi County in Guangyuan City, Nanjiang and Tongjiang Counties in Bazhong City, and Xuanhan County in Dazhou City. Vertebrate fossils are rare in northern Sichuan. Currently, Jurassic tetrapod tracks are only known from Guangyuan and Xuanhan. Young (1943) named the ichno taxa Kuangyuanpus szechuanensis from the midJurassic Xiashaximiao Formation, and considered it the tracks of a saurischian dinosaur. Zhen et al. (1989) instead attributed K. szechuanensis to the archosaurian tracks of 
Batrachopus szechuanensis. Lockley et al. (2010) considered K. szechuanensis likely to represent crocodilian swim tracks. Xing et al. (2017) described two relatively small tridactyl cf. Anomoepus tracks from Middle Jurassic Xintiangou Formation of Xuanhan.

During regional geological surveys of northern Sichuan, atoposaurid crocodyliforms from the Cangxi Formation and theropod teeth from the Bailong Formation have been documented ( $\mathrm{Gu} \&$ Liu, 1997). However, neither descriptions nor figures are available from these records. Peng (1995, 1996) described Sichuanosuchus huidongensis from the Lower Jurassic Shangshaximiao Formation of Zigong. Wu et al. (1997) described another species of Sichuanosuchus (S. shuhanensis), which was reported to be from the Early Cretaceous strata of Sichuan, but not necessarily from North Sichuan.

Local residents of Goujiayuanzi Natural village (Fig. 1), Chaoyang Village, Tongjiang County, Bazhong City have long considered a huge sandstone slab in the village courtyard to contain "chicken footprints". On October 1st, 2020, fiveyear-old Zherui YANG and his family reported to the first author that these "chicken footprints" might be non-avian theropod tracks. On October $9^{\text {th }}$, the main authors visited the tracksite (GPS: $\left.31^{\circ} 57^{\prime} 0.46^{\prime \prime} \mathrm{N}, 107^{\circ} 19^{\prime} 45.07^{\prime \prime E}\right)$. The slab does contain multiple non-avian dinosaur tracks, making them the first Cretaceous dinosaur tracks to be found on the northern margin of the Sichuan Basin. Zhang et al (in press) briefly described these tracks, and classified in Eubrontes. This article will describe Tongjiang tracks in detail, and discusses the behavior and potential trackmakers.

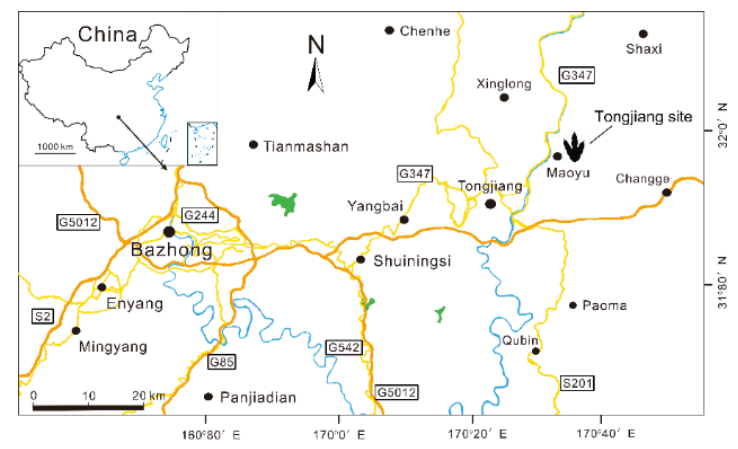

Figure 1. Map showing the location of Tongjiang site in the Lower Cretaceous Cangxi Formation of Sichuan Province, China (Note: Institutional abbreviations: $\mathrm{TJ}=$ Tongjiang site, Bazhong City, Sichuan Province, China)

Materials and methods

Maximum length (ML), maximum width (MW), divarication angle (II-IV), pace length (PL), stride length (SL), pace angulation (PA), and rotation (R) were measured according to the standard procedures of Leonardi (1987) and Lockley and Hunt (1995). The mesaxony of tridactyl tracks (the degree to which digit III protrudes anteriorly beyond the digits II and IV) was calculated according to the methods of Olsen (1980), Weems (1992), and Lockley (2009). Speed (v) estimates were derived using Alexander's (1976) formula: $\mathrm{v}=$ $0.25 \mathrm{~g} 0.5 \times \mathrm{SL}^{1.67} \times \mathrm{h}^{-1.17}$, where $\mathrm{g}=$ gravitational acceleration in $\mathrm{m} / \mathrm{sec} ; \mathrm{SL}=$ stride length; and $\mathrm{h}=$ hip height. In small theropods, hip height was estimated as 4.5 times foot length, using the ratio for small theropods proposed by Thulborn (1990). In large theropods, hip height was estimated as 4.9 times the track length (Thulborn, 1990) and body length was estimated to be 2.63 times the hip height (Xing et al. 2009)

\section{Geological setting}

The Sichuan Basin of Southwest China is filled with thick Lower Paleozoic-Cenozoic deposits. During the Early Cretaceous, the depocenter of the basin 
was mainly distributed at the front edge of Longmenshan Fault Zone, with the thickest areas primarily located in Guangyuan and Bazhong, in northern Sichuan. The strata of this region are characterized by a set of rhythmic red thick-bedded fine sandstones and have been termed the Chengqiangyan Group by Zhao and Huang (1931). Wang et al. (1982) divided the strata into four formations: the Cangxi, Bailong, Qiqusi and Gudian from bottom to top.

The Cangxi Formation is $452 \mathrm{~m}$ thick (Fig. 2). It is composed of purple-gray, brick red and other chromatic debris, feldspathic quartz sandstone, siltstone, and mudstone. It is interbedded with rhythmic layerings of unequal thickness and rarely with conglomerate bands and lenses. It is rich in bivalve and ostracod fossils. The bottom of the Cangxi Formation forms a non-angular unconformity with the mixed purple-red mudstone and gray-purple fine sandstone and siltstone at the top of the underlying Penglaizhen Formation. The top of the Cangxi Formation is conformable with the gray-white massive sandstone and conglomerate at the base of the overlying Bailong Formation (Gu \& Liu, 1997). Ostracods (such as Djungarica, Darwinula, and Jingguella), bivalves (such as Nakamuranaia and Nippononaia), Estherians (such as Yanjiestheria), and isolated crocodyliform elements are abundant throughout (Gu \& Liu, 1997).

Paleomagnetic and biostratigraphic data has identified the Cangxi Formation as Berriasian (Bureau of Geology and Mineral Resources of Sichuan Province, 1991; Compiling Group of Continental Mesozoic Stratigraphy and Palaeontology in Sichuan Basin of China, 1982; Zhuang et al., 1988). Hou et al. (2020) reported the pollen assemblages of the Cangxi-Bailong formations to be dominated by Classopollis and to also include Dicheiropollis, Cycadopites, 176

Cyathidites, Deltoidospora and Cicatricosisporites. This pollen data constrains the age to ValanginianHauterivian. The age of the Cangxi Formation is constrained to Berriasian-Valanginian herein. Pollen assemblages show that the phytocenosis during this period was dominated by Cheirolepidiaceae, reflecting the very dry climate (Hou et al., 2020). In the sedimentary sequence, the pollen assemblages show insignificant changes, which may indicate a highly stable and dry climate (Hou et al., 2020).

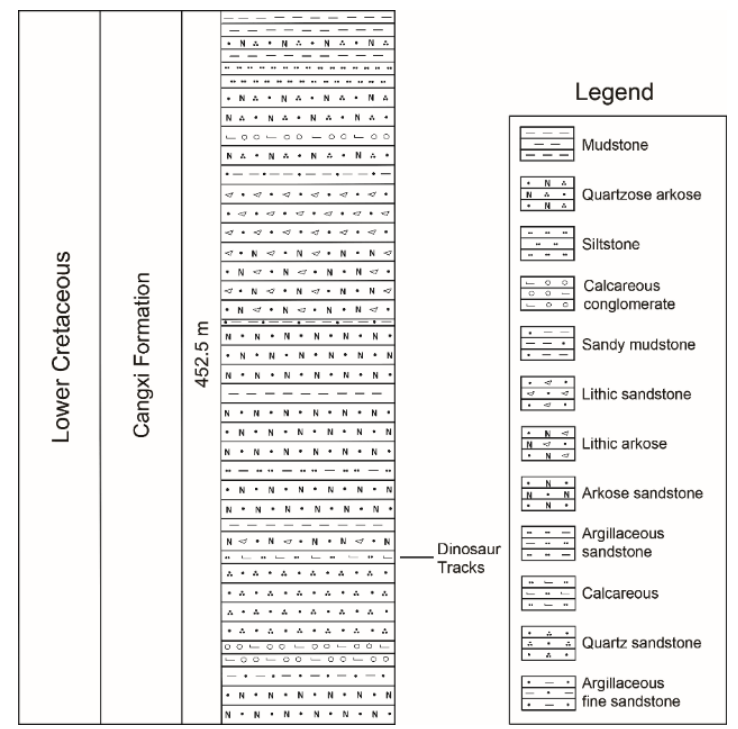

Figure 2. Stratigraphic section showing position of track-bearing level of Tongjiang site in the Lower Cretaceous Cangxi Formation of Sichuan Province, China.

The dinosaur tracks here described are located on Cangxi Formation siltstone, which is exposed in a large rock fall. There are relatively small ripple marks developed on the bedding plane, and the dinosaurs' direction of travel was cut to the paleocurrent direction.

\section{Ichnotaxonomy}

\section{Description}


Trackway TJ-T1 is a large tridactyl trackway composed of 5 tracks, cataloged asTJ-T1-R1 to R3 (Figs. 3, 4; Table 1). It extends for $5.5 \mathrm{~m}$ in total length. The average track length is $36.7 \mathrm{~cm}$. The mean length/width ratio is 1.2 . The mean length/width ratio of the anterior triangle is 0.42 , indicating weak mesaxony (Lockley, 2009). The weak projection of digit III and the increased digital width are interpreted as adaptations for graviportality (Lallensack et al., 2020).

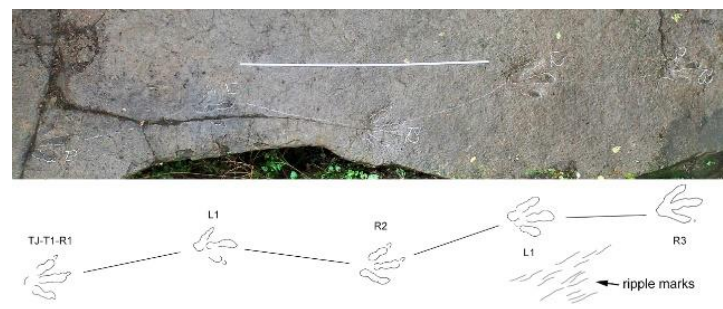

Figure 3. Photograph and interpretative outline drawing of the theropod trackway from the Tongjiang site, Sichuan Province, China.

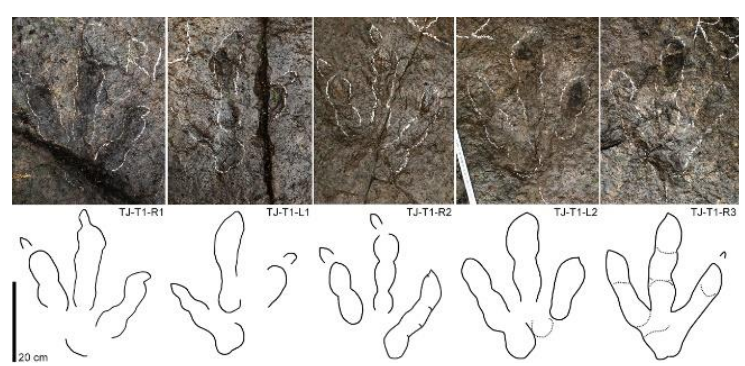

Figure 4. Photograph and interpretative outline drawing of the theropod tracks from the Tongjiang site, Sichuan Province, China.

TJ-T1-R3 is the best-preserved single track. Digit III of TJ-T1-R3 projects the farthest anteriorly, followed by digits IV and II. There are relatively large metatarsophalangeal pad traces of digit IV, near the axis of digit III, and these pads are separated from those of digit II by a larger gap. The deep, concave digit impressions retain pad impressions, with a formula of x-2-3-4-x. Each digit has a sharp claw mark, with that of digit IV being the longest and most distinctive. The digits have relatively wide divarication angles (averaging $63^{\circ}$ ) between digit II and IV. The divarication angle between digits II and III is almost equal to that between digits III and IV. The morphological characteristics of the other tracks of TJ-T1 are generally consistent with those of TJ-T1. The average pace angulation is $166^{\circ}$, and the footprint length to pace length ratio is $1: 3.51$.

\begin{tabular}{l|cccccccc}
\hline TJ-T1- & ML & MW & L/W & II-IV & PL & SL & PA & M \\
\hline R1 & 37.0 & 35.0 & 1.1 & 67 & 134.5 & 267.0 & 168 & 0.38 \\
L1 & 36.0 & 32.5 & 1.1 & 74 & 134.0 & 255.0 & 159 & 0.55 \\
R2 & 38.0 & 31.0 & 1.2 & 58 & 125.5 & 245.5 & 170 & 0.38 \\
L2 & 37.5 & 30.5 & 1.2 & 59 & 121.0 & - & - & 0.42 \\
R3 & 35.0 & 29.0 & 1.2 & 58 & - & - & - & 0.39 \\
Mean & 36.7 & 31.6 & 1.2 & 63 & 128.8 & 255.8 & 166 & 0.42 \\
\hline
\end{tabular}

Table 1. Measurements (in $\mathrm{cm}$ and degree) of theropod tracks from the Lower Cretaceous Cangxi Formation in the northern margin of the Sichuan Basin (Note: Abbreviations: ML: maximum length; MW: maximum width; R: rotation; PL: pace length; SL: stride length; PA: pace angulation; $\mathrm{L} / \mathrm{W}$, is dimensionless; $\mathrm{M}$, mesaxony).

For theropods, Thulborn (1990) first suggested that hip height $\mathrm{h}=4.9 \times$ foot length. Relative stride length $(\mathrm{SL} / \mathrm{h})$ may be used to determine whether the trackmaker was walking $(\mathrm{SL} / \mathrm{h} \leq 2.0)$, trotting $(2<\mathrm{SL} / \mathrm{h}<2.9)$, or running $(\mathrm{SL} / \mathrm{h} \geq 2.9$ ) (Alexander, 1976; Thulborn, 1990). The SL/h ratio of TJ-T1 is 1.42 , and this suggests walking. Using the equation to estimate speed from trackways (Alexander, 1976), the mean locomotion speed of the trackmaker is $6.8 \mathrm{~km} / \mathrm{h}$. The body length of the TJT1 trackmaker of was approximately $4.73 \mathrm{~m}$, calculated using the average hip height to body length ratio of 1:2.63 (Xing et al., 2009).

\section{Discussion}

TJ-T1 is typical of theropod tracks, and it is characterized by weak mesaxony, which is typical 
for footprints of the ichno- or morphofamily Eubrontidae (0.37-0.58, Lockley, 2009). Eubrontes morphotype tracks ( $>25 \mathrm{~cm}$, Olsen et al., 1998) are common in the Jurassic and Cretaceous of China (Xing et al., 2016a). The mesaxony and length/width ratios is 0.58 and 1.7 , respectively, for Lower Jurassic Eubrontes giganteus from the Hitchcock collection (Lockley, 2009), which differ from those of TJ-T1 (0.42 and 1.2). However, other Lower Jurassic Hitchcock specimens assigned to Eubrontes have wider interdigital divarication angles and lower length/width ratios (some measure 0.44 and 1.3) (Ishigaki \& Fujisaki, 1989), which is quite close to TJ-T1. In addition, the ratio of digit III to footprint length is 0.68 , which is very close to $\sim 0.7$ of E. giganteus, and the mean value (0.64) derived from a large sample of Eubrontes from Utah (Lockley et al., 2021).

Two metatarsophalangeal pad traces are reported in the type specimen of Eubrontes (AC 151: Olsen et al., 1998) and Eubrontes zigongensis (Xing et al., 2014), but is not a universal feature. TJ-T1 lacks distinct metatarsophalangeal pad traces from digit II, throughout the trackway, with the exception of a faint trace in TJ-T1-L2, probably due to the preservation and a less developed digit II metatarsophalangeal pad.

The Early Cretaceous theropod tracks in southwest Sichuan Basin, as well as the Mishi-Jiangzhou Basin (Xichang Basin), are fairly abundant. Theropod tracks from southwest Sichuan Basin have mainly been discovered in the Jiaguan Formation (Barremian-Albian), and include Grallator, Eubrontes, Minisauripus, cf. Irenesauripus, Velociraptorichnus, cf. Dromaeopodus, and coelurosaur tracks. Theropod tracks from Mishi-Jiangzhou Basin were discovered in the underlying Feitianshan Formation (Berriasian-Barremian) and the overlying Xiaoba Formation (Aptian-Albian/Cenomanian). The 178 former yielded Grallator-type, Eubrontes-type, Minisauripus, cf. Dromaeopodus and Siamopodus. The latter has yielded Grallator- type, Eubrontestype and Velociraptorichnus (Xing \& Lockley, 2016).

The TJ-T1 tracks are similar to the Eubrontes track HX-T3 (30 $\mathrm{cm}$ in length), from the Jiaguan Formation, and the Eubrontes track BJA-T4 (23.9 $\mathrm{cm}$ in length) from the Feitianshan Formation. The mesaxony and length/width ratios of HX-T3 is 0.37 and 1.4 (Xing et al., 2015), and the mesaxony and length/width ratios of BJA-T4 is 0.46 and 1.4 (Xing et al., 2016b). This demonstrates consistency across Early Cretaceous theropods in the north and south of Sichuan Basin (Zhang et al., in press).

Eubrontes is reported from the Late Triassic to the Late Cretaceous and corresponding to mediumlarge sized theropods of various species, such as the Early Jurassic Dilophosaurus (Morales \& Bulkley, 1996) and the Early Cretaceous allosaur Acrocanthosaurus (Farlow, 2001; Farlow et al., 2006; Adams et al., 2010). However, it is generally more common in the Early Jurassic, where is one of the dominant members of the Lower Jurassic Biochron (sensu Lucas, 2007). The distribution of Eubrontes in the Cretaceous in China and globally is less well known and still under investigation (Xing et al., in review). Except for Tyrannosauroids (such as Yutyrannus Xu et al., 2012), Early Cretaceous medium-large sized theropods are rare and poorly preserved in China (Dong, 1973; Brusatte et al., 2012). Thus, potential trackmakers of the Early Cretaceous Eubrontes of China can only be very generally inferred, they may include all medium-large sized non- deinonychosaurian theropods.

\section{Conclusions}

Although the number is limited, the track records 
are consistent with other Early Cretaceous theropod tracks from the Sichuan Basin in morphology. The tetrapod ichnofauna described here is the only credible evidence of dinosaurian faunas in this region. Thus, it is a type 1 deposit (correspondence between bones and tracks) where only contains tracks (Lockley, 1991). The report is consistent entirely with the widespread evidence that the ichnofaunas of the Sichuan Basin region are consistently theropod dominated.

\section{Acknowledgments}

We thank National Natural Science Foundation of China (41772008), and the 111 project (B20011), China.

\section{References}

Adams, T.L., Strganac, C., Polcyn, M.J., \& Jacobs, L.L. (2010). High resolution threedimensional laser-scanning of the type specimen of Eubrontes (?) glenrosensis Shuler, 1935, from the Comanchean (Lower Cretaceous) of Texas: Implications for digital archiving and preservation. Palaeontologia Electronica, 13(3), 11.

Alexander, R.M. (1976). Estimates of speeds of dinosaurs. Nature, 261, 129-130. https://doi.org/10.1038/261129a0

Brusatte, S.L., Benson, R.B.J., \& Xu, X. (2012). A reassessment of Kelmayisaurus petrolicus, a large theropod dinosaur from the Early Cretaceous of China. Acta Palaeontologica Polonica, 57(1), 65-72. https://doi.org/10.4202/app.2010.0125

Bureau of Geology and Mineral Resources of Sichuan Province. (1991). Regional Geology of Sichuan Province. Beijing: Geological Publishing House; p. 682 in Chinese.

Compiling Group of Continental Mesozoic Stratigraphy and Palaeontology in Sichuan
Basin of China. (1982). Continental Mesozoic Stratigraphy and Palaeontology in Sichuan Basin of China. Chengdu: People's Publishing House of Sichuan; p. 151-163 in Chinese.

Dong, Z.M. (1973). Dinosaurs from Wuerho. Institute of Vertebrate Paleontology and Paleoanthropology Memoir, 11, 45-52.

Farlow, J.O. (2001). Acrocanthosaurus and the maker of Comanchean largetheropod footprints. In Tanke D.H., \& Carpenter K. (Eds.), Mesozoic Vertebrate Life (pp. 408427). Bloomington: Indiana University Press.

Farlow, J.O., Langston, W., Deschner, E.E., Solis, R., Ward, W., Kirkland, B.L., Hovorka, S., Reece T.L., \& Whitcraft, J. (2006). Texas Giants: Dinosaurs of the Heritage Museum of the Texas Hill Country. Canyon Lake: Heritage Museum of the Texas Hill Country.

Gu, X.D. \& Liu, X.H. (1997). Stratigraphy (Lithostratic) of Sichuan Province. Wuhan: China University of Geosciences Press; p. 417 in Chinese.

Hou, X.W., Shi, Z.J., Sun, Z.X., Tan, Z.Y., \& Tian, X.S. (2020). The sporopollen assemblages in the Early Cretaceous red sediments in Cangxi area, northern Sichuan Basin and their geological significance. Geological Review, 66(3), 727-738. https://doi.org/10.16509/j.georeview.2020.0 3.014

Ishigaki, S., \& Fujisaki, T. (1989). Three dimensional representation of Eubrontes by the method of moire topography. In Gillette, D.D., \& Lockley, M.G. (Eds). Dinosaur Tracks and Traces (pp. 421-425). New York: Cambridge University Press.

Lallensack, J.N., Engler, T., \& Barthel, H.J. (2020). Shape variability in tridactyl dinosaur footprints: the significance of size and function. Palaeontology, 63(2), 203-228. 
https://doi.org/10.1111/pala.12449

Leonardi, G. (1987). Glossary and manual of tetrapod footprint palaeoichnology. Brazil: Departamento Nacional de Producao Mineral.

Lockley, M.G. (1991). Tracking dinosaurs-a new look at an ancient world. New York: Cambridge University Press.

Lockley, M.G. (2009). New perspectives on morphological variation in tridactyl footprints: clues to widespread convergence in developmental dynamics. Geological Quarterly, 53, 415-432.

Lockley, M.G., \& Hunt, A.P. (1995). Dinosaur tracks and other fossil footprints of the western United States. New York: Columbia University Press.

Lockley, M.G., Breithaupt, B. Matthews, N., Shibata, K., \& Hunt-Foster, R. (2021). A preliminary report on an Early Jurassic Eubrontes-dominated tracksite in the Navajo formation at the Mail Station Dinosaur Tracksite, eastern Utah. New Mexico Museum of Natural History and Science Bulletin, 82, 195-208.

Lockley, M.G., Li, R., Matsukawa, M., \& Li, J. (2010). Tracking Chinese crocodilians: Kuangyuanpus, Laiyangpus and implications for naming crocodylian and crocodylian-like tracks and associated ichnofacies. New Mexico Museum of Natural History and Science, Bulletin, 51, 99-108.

Lucas, S. G. (2007). Tetrapod footprint biostratigraphy and biochronology. Ichnos, 14(1-2), 5-38. https://doi.org/10.1080/1042094060100679 $\underline{2}$

Morales, M., \& Bulkley, S. (1996). Paleoichnological evidence for a theropod dinosaur larger than Dilophosaurus in the Lower Jurassic Kayenta Formation. The
Continental Jurassic. Museum of Northern Arizona Bulletin, 60, 143-145.

Olsen, P.E. (1980). Fossil great lakes of the Newark Supergroup in New Jersey. 52nd Annual Meeting in Newark, New Jersey, Paper No. 352-398.

Olsen, P.E., Smith, J.B., \& McDonald, N.C. (1998). Type material of the type species of the classic theropod footprint genera Eubrontes, Anchisauripus and Grallator (Early Jurassic, Hartford and Deerfield Basins, Connecticut and Massachusetts, U.S.A.). Journal of Vertebrate Paleontology, 18(3), 586-601. https://doi.org/10.1080/02724634.1998.100 $\underline{11086}$

Peng, G.Z. (1995). A new protosuchian from the Late Jurassic of Sichuan, China. In Sun AL, \& Wang YQ (Eds.), Sixth Symposium on Mesozoic Terrestrial Ecosystems and Biota, Short Papers (pp. 63-68). Beijing: China Ocean Press.

Peng, G.Z. (1996). A Late Jurassic protosuchian Sichuanosuchus huidongensis from Zigong, Sichuan Province. Vertebrata PalAsiatica, 34, 269-278.

Thulborn, T. (1990). Dinosaur Tracks. London: Chapman \& Hall.

Wang, M.J., Chen, M.K., Guo, M.M., Zeng, L.K., $\&$ Ye, C.H. (1982). The age of the wall rocks in Sichuan Basin. Journal of Stratigraphy, 16(2), 92-100.

Weems, R.E. (1992). A re-evaluation of the taxonomy of Newark Supergroup saurischian dinosaur tracks, using extensive statistical data from a recentlyexposed tracksite near Culpeper Virginia. In Sweet P.C. (Ed.), Proceedings of the 26th Forum on the geology of industrial minerals. Virginia: Division of Mineral Resources; p. 113-127.

Wu, X.C., Sues, H.D., \& Dong, Z.M. (1997). Sichuanosuchus shuhanensis, a new? Early 
Cretaceous protosuchian (Archosauria: Crocodyliformes) from Sichuan (China), and the monophyly of Protosuchia. Journal of Vertebrate Paleontology, 17, 89-103. https://doi.org/10.1080/02724634.1997.100 $\underline{10956}$

Xing, L.D., Harris, J.D., Feng, X.Y., \& Zhang, Z.J. (2009). Theropod (Dinosauria: Saurischia) tracks from Lower Cretaceous Yixian Formation at Sihetun, Liaoning Province, China and Possible Track Makers. Geological Bulletin of China, 28(6), 705-712.

Xing, L.D., Peng, G.Z., Ye, Y., Lockley, M.G., McCrea, R.T., Currie, P.J., Zhang, J.P., \& Burns, M.B. (2014). Large theropod trackway from the Lower Jurassic Zhenzhuchong Formation of Weiyuan County, Sichuan Province, China: Review, new observations and special preservation. Palaeoworld, 23, 285-293. https://doi.org/10.1016/j.palwor.2014.10.01 $\underline{0}$

Xing, L.D., Lockley, M.G., Zhang, J.P., Klein, H., Marty, D., Peng, G.Z., Ye, Y., McCrea, R.T., Persons, W.S.IV., \& Xu, T. (2015). The longest theropod trackway from East Asia, and a diverse sauropod-, theropod-, and ornithopod-track assemblage from the Lower Cretaceous Jiaguan Formation, southwest China. Cretaceous Research, 56, 345-362.

$\underline{\text { https://doi.org/10.1016/j.cretres.2015.05.00 }}$ $\underline{8}$

Xing, L.D., \& Lockley, M.G. (2016). Early Cretaceous dinosaur and other tetrapod tracks of southwestern China. Science Bulletin, 61(13), 1044-1051. https://doi.org/10.1007/s11434-016-1093-Z

Xing, L.D., Lockley, M.G., \& Zhang, J.P. (2016a). Early Cretaceous dinosaur and other tetrapod tracks of southwestern China.
Ningbo: Ningbo Publishing House.

Xing, L.D., Lockley, M.G., Yang, G., Cao, J., McCrea, R.T., Klein, H., Zhang, J.P., Persons, W.S.IV., \& Dai, H. (2016b). A diversified vertebrate ichnite fauna from the Feitianshan Formation (Lower Cretaceous) of southwestern Sichuan, China. Cretaceous Research, 57, 79-89. https://doi.org/10.1016/j.cretres.2015.08.00 $\underline{5}$

Xing, L.D., Lockley, M.G., Wang, Y.D., Pole, M.S., Klein, H., Peng, G.Z., Xie, X.P., Zhang, G.Q., Deng, C.T., \& Burns, M.E. (2017). New Middle Jurassic dinosaur track record from northeastern Sichuan Province, China. Swiss Journal of Palaeontology, 136(2), 359-364. https://doi.org/10.1007/s13358-016-0123-4

Xing, L.D., Lockley, M.G., Klein, H., Zhang, L.J., Romilio, A., Persons, W.S.IV., Peng, G.Z., Ye, Y., Wang, \&M.Y., (in review). The new ichnotaxon Eubrontes nobitai ichnosp. nov. and other Saurischian tracks from the Lower Cretaceous Sichuan Province and a review of Chinese Eubrontes type tracks. Journal of Palaeogeography.

Xu, X., Wang, K., Zhang, K., Ma, Q., Xing, L., Sullivan, C., Hu, D., Cheng, S., \& Wang, S. (2012). A gigantic feathered dinosaur from the Lower Cretaceous of China. Nature, 484(7392), 92-95. https://doi.org/10.1038/nature10906

Young, C.C. (1943). Note on some fossil footprints in China. Bulletin of the Geological Society of China, 13(3-4), 151-154.

Zhao, Y.Z., \& Huang J.Q. (1931). The geological study of Qinling and Sichuan areas. Geological Reports, 9, 1-47.

Zhen, S.N., Li, J.J., Rao, C.G., Mateer, N.J., \& Lockley, M.G. (1989). A review of dinosaur footprints in China. In Gillette D.D.\& Lockley M.G. (Eds), Dinosaur Tracks and 
Traces (pp. 187-197). Cambridge:

Cambridge University Press.

Zhuang, Z.H., Tian, D.X., Ma, X.H., Ren ,X.F., Jiang, X.C., \& Xu, S.J. (1988). A paleomgnetic study along the Yaan-Tianquan Cretaceous-Eogene section in Sichuan Basin.
12(3), 224-228.

Zhang, Y., Tong, B.L., \& Xing, L.D. (in press). The discovery of dinosaur footprints in Cretaceous strata from the northern margin of Sichuan Basin. Geological Bulletin of China.

Geophysical \& Geochemical Exploration,

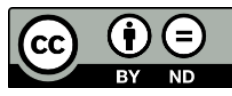

Publisher's note: Eurasia Academic Publishing Group (EAPG) remains neutral with regard to jurisdictional claims in published maps and institutional affiliations.

Open Access This article is licensed under a Creative Commons Attribution-NoDerivatives 4.0 International (CC BY-ND 4.0) licence, which permits copy and redistribute the material in any medium or format for any purpose, even commercially. The licensor cannot revoke these freedoms as long as you follow the licence terms. Under the following terms you must give appropriate credit, provide a link to the license, and indicate if changes were made. You may do so in any reasonable manner, but not in any way that suggests the licensor endorsed you or your use. If you remix, transform, or build upon the material, you may not distribute the modified material.

To view a copy of this license, visit https://creativecommons.org/licenses/by-nd/4.0/. 